\title{
Admission Values of Plasma Biomarkers Predict the Short-Term Outcomes in Acute Aortic Dissection
}

\author{
Nan Xie, ${ }^{1,2}$ Wei Zhang, ${ }^{1,2}$ Hong Li, ${ }^{1,2}$ Jing Zhou, ${ }^{1,2}$ Haihong Zhang, ${ }^{1,2}$ Xinyi Yang, ${ }^{1,2}$ Liqun Zou, ${ }^{1,2}$ Zhi Wan ${ }^{1,2}$ \\ ${ }^{1}$ Emergency Department of West China Hospital, Sichuan University/West China School of Nursing, Sichuan University; ${ }^{2}$ Institute \\ of Disaster Medicine, Sichuan University
}

\section{ABSTRACT}

Background and aims: Acute aortic dissection (AAD) is an emergency disease with high misdiagnosis rate and mortality. The aim of the present study is to explore the impact of blood-related biomarkers, specifically D-dimer, on in-hospital outcomes of patients with AAD.

Materials and methods: A total of 345 patients in our hospital from December 2013 to April 2017 were included. The cutoff value for D-dimer and LDL-C were set as $5.9 \mathrm{mg} / \mathrm{l}$ and $1.45 \mathrm{mg} / \mathrm{l}$, respectively. The univariate and multivariate logistic regression models were used to identify the independently prognostic predictors.

Results: The results showed that patients with type A AAD had higher risk of in-hospital mortality compared with those with type B disease. Moreover, results revealed the type A AAD (OR 6.382, 95\%CI: 2.423 to 16.812 ), D-dimer (OR 2.160, 95\%CI: 1.072 to 4.350), and LDL-C (OR 0.373, $95 \%$ CI: 0.148 to 0.940 ) were independently associated with in-hospital mortality. Subgroup analysis suggested that D-dimer (OR 2.295, 95\% CI: 1.140 to 4.622) was an independently prognostic factor in type A AAD.

Conclusion: In summary, D-dimer $\geq 5.9 \mathrm{mg} / \mathrm{L}$ and type A $\mathrm{AAD}$ were independently associated with in-hospital mortality in $\mathrm{AAD}$ patients. Moreover, subgroup analysis proved that the elevated $\mathrm{D}$-dimer was related to poor prognosis in type $\mathrm{AAAD}$.

\section{INTRODUCTION}

Acute aortic dissection (AAD) is increasing in incidence in the emergency department; it comes with a negative influence in prognosis [Aboyans 2017; Nienaber 2012]. A study indicated that the incidence of $\mathrm{AAD}$ showed an increasing trend [Meszaros 2000], which still carries a high in-hospital mortality approaching $40 \%$ in the short-term [Kalkan 2015]. Therefore, AAD recently has become a hot topic. Also, it was reported that the early misdiagnosis rate is approaching $38 \%$, despite imaging techniques like CT or contrastenhanced CT. Moreover, a blood test is fast and convenient for the diagnosis of other diseases. So, it is necessary for the

Received October 23, 2020; accepted November 10, 2020.

Correspondence: Liqun Zou (zz9212211@126.com) and Zhi Wan (303680215@qq.com). patient suspected of having AAD to be tested. Research has reported that high levels of plasma biomarkers related with inflammation include D-dimer [Wen 2013; Eggebrecht 2014; Nazerian 2014; Sbarouni 2017; Hata 2007; Ohlmann 2006] and CRP [Wen 2013; Schillinger 2002].

D-dimer is a degradation product of fibrin, which recently was regarded as an effect of plasma biomarkers. Furthermore, CRP and D-dimer now have become a hotspot of research around the world [Wen 2013]. Many studies have found that $\mathrm{CRP}$ and D-dimer play an important role in diagnosis of $\mathrm{AAD}$. Another study has indicated that with the level of D-dimer increasing, the in-hospital mortality of AAD show an increasing rate [Sbarouni 2017; Peng 2015]. However, there is no research about the use of a combination of biomarkers for short-term prognosis of $\mathrm{AAD}$, and no one has done research about different types of AAD. Sakakura et al demonstrated that peak CRP is a predicted factor in patients with $\mathrm{AAD}$ in a short-term outcome [Sakakura 2010], and Tian et al indicated that high admission D-dimer levels can increase the incidence mortality of AAD [Tian 2014]. Although there are few previous studies evaluating the prognostic factors in patients with $\mathrm{AAD}$, the sample sizes in some studies were small [Peng 2015; Shimony 2011]. This is the first study to research the shortterm prognosis of AAD in the West China District, and we enrolled a large number of patients. Thus, the objective of our research was to elucidate the factors that affected the inhospital outcome of patients with AAD.

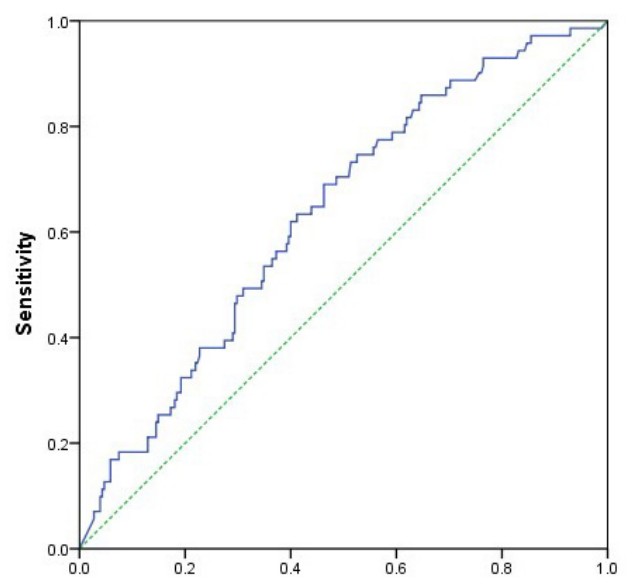

Figure 1. Diagnostic value of D-dimer for in-hospital death. 
Table 1. Demographics and clinicopathological characteristics of patients diagnosed with AAD in the present study

\begin{tabular}{|c|c|c|c|}
\hline Patients number & 270 & 75 & - \\
\hline Type B AAD, n (\%) & $128(47.4)$ & $12(16)$ & $<.001$ \\
\hline Age (years) & $50.67 \pm 11.49$ & $52.47 \pm 12.52$ & .242 \\
\hline History of smoking, n (\%) & $164(60.7)$ & $33(44)$ & .008 \\
\hline History of hypertension, $\mathrm{n}(\%)$ & $182(67.4)$ & $45(60)$ & .271 \\
\hline History of drinking, n (\%) & $140(51.9)$ & $27(36)$ & .019 \\
\hline Admission SBP (mm Hg) & $147.54 \pm 32.42$ & $132.69 \pm 34.1$ & .01 \\
\hline Admission DBP (mm Hg) & $84.00 \pm 22.64$ & $74.29 \pm 20.86$ & .01 \\
\hline $\mathrm{HDL}-\mathrm{C}, \mathrm{mmol} / \mathrm{L}$ & $1.27 \pm 0.51$ & $3.32 \pm 18.2$ & .066 \\
\hline LDL-C, mmol/L & $3.03 \pm 12.57$ & $2.14 \pm 0.76$ & .537 \\
\hline $\mathrm{TG}, \mathrm{mmol} / \mathrm{L}$ & $2.49 \pm 10.26$ & $1.46 \pm 1.1$ & .386 \\
\hline $\mathrm{TC}, \mathrm{mmol} / \mathrm{L}$ & $3.96 \pm 1.06$ & $6.48 \pm 23.37$ & .079 \\
\hline $\mathrm{Na}, \mathrm{mmol} / \mathrm{L}$ & $138.65 \pm 3.43$ & $138.60 \pm 3.74$ & .911 \\
\hline $\mathrm{K}, \mathrm{mmol} / \mathrm{L}$ & $3.76 \pm 0.56$ & $5.16 \pm 10.89$ & .035 \\
\hline $\mathrm{Ca}, \mathrm{mmol} / \mathrm{L}$ & $3.69 \pm 17.23$ & $2.16 \pm 0.13$ & .433 \\
\hline $\mathrm{Mg}, \mathrm{mmol} / \mathrm{L}$ & $0.83 \pm 0.15$ & $0.86 \pm 0.12$ & .100 \\
\hline
\end{tabular}

$\mathrm{SBP}=$ systolic blood pressure, $\mathrm{DBP}=$ diastolic blood pressure, $\mathrm{CRP}=\mathrm{C}$-reactive protein, $\mathrm{HDL}-\mathrm{C}=$ high-density lipoprotein cholesterol, LDL-C $=$ low-density lipoprotein cholesterol, TG = triglyceride, TC = total cholesterol, $\mathrm{NA}=$ sodium, $\mathrm{K}=$ kalium, $\mathrm{Ca}=$ calcium, $\mathrm{Mg}=$ magnesium

\section{MATERIALS AND METHODS}

Patients and data collection: Between December 1, 2013 and April 30, 2017, all the patients consecutively admitted to the emergency units of our hospital (Department of Emergency, West China Hospital, Sichuan University) were enrolled in this retrospective study. Among these 345 patients, 270 patients survived and 75 patients died in a short time. The inclusion criteria were: 1) diagnosed with AAD by imaging examination (CT/MRI); 2) the data from hospital HIS system; 3) diagnosis of AAD; and 4) venous blood was drawn in the first 48 hours after admission. The patients who did not have the blood test were excluded. This study was approved by the Ethics Committee of West China Hospital and for such studies, no informed consent is required. The methods were carried out in accordance with the approved guidelines.

Venous blood measurements: All venous blood was obtained from the patients in the emergency department after admission (within 48 hours). The receiver-operating characteristic (ROC) curve and Youden index (Youden index = sensitivity + specificity - 1) were applied to select the cutoff value of blood laboratory tests, including D-dimer, CRP, HDL-C, LDL-C,
TG, TC, $\mathrm{Na}, \mathrm{K}, \mathrm{Ca}$, and $\mathrm{Mg}$. The cutoff value for $\mathrm{D}$-dimer, CRP, HDL-C, LDL-C, TG, TC, $\mathrm{Na}, \mathrm{K}, \mathrm{Ca}$, and $\mathrm{Mg}$ was set as $5.9 \mathrm{mg} / \mathrm{L}, 106.5 \mathrm{mg} / \mathrm{L}, 1.505 \mathrm{mmol} / \mathrm{L}, 1.455 \mathrm{mmol} / \mathrm{L}$, $0.655 \mathrm{mmol} / \mathrm{L}, \quad 3.605 \mathrm{mmol} / \mathrm{L}, 136.55 \mathrm{mmol} / \mathrm{L}, 4.025$ $\mathrm{mmol} / \mathrm{L}, 2.145 \mathrm{mmol} / \mathrm{L}$, and $0.835 \mathrm{mmol} / \mathrm{L}$, respectively.

Statistical analysis: Statistical analysis was performed using IBM SPSS Statistics for Windows, Version 22 (IBM Corp, released 2013, Armonk, NY, USA). All continuous variables were presented as means \pm standard deviations (S.D.) and categorical variables were expressed as percentages and frequencies. Patients who died in hospital were divided into one group, and the remaining patients were placed into another group. Chi-squared test and student t-test were used to compare the differences between the two groups. The impact of variables on in-hospital mortality were identified by the univariate and multivariate logistic analysis. Factors with $P$ values $<0.1$ in the univariate analysis were included in the multivariate analysis. The cutoff values of blood-based parameters, such as D-dimer and CRP, were determined by using receiver operating characteristic (ROC) and Youden index. Youden index $=$ sensitivity + specificity -1 . A variable with a two-tailed value of $P<.05$ was considered statistically significant. 
Table 2. Univariate logistic regression analyses of relationship between clinical features and in-hospital mortality in patients with AAD.

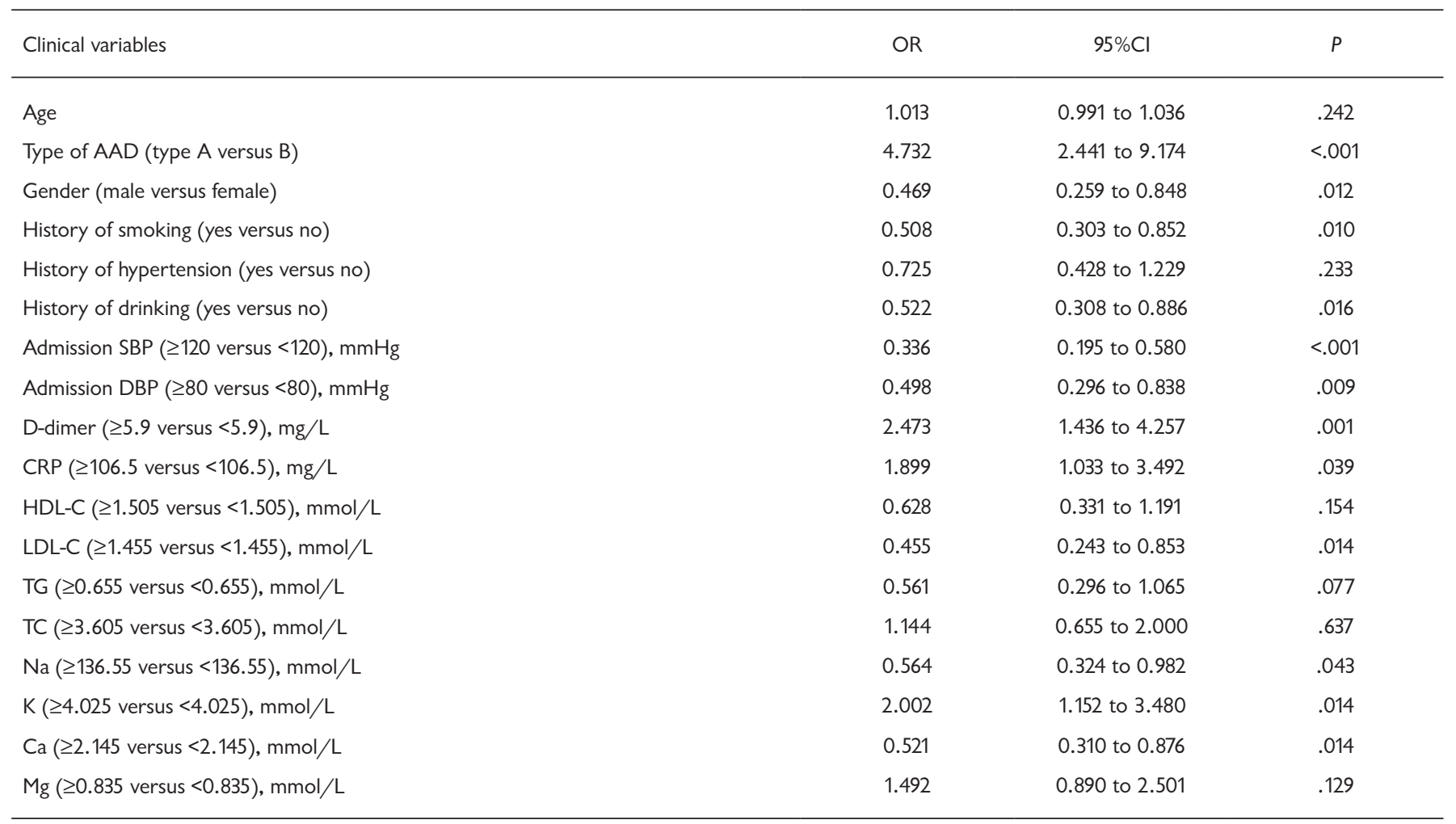

$\mathrm{OR}=$ odds ratio, $\mathrm{Cl}=$ confidence interval, $\mathrm{SBP}=$ systolic blood pressure, $\mathrm{DBP}=$ diastolic blood pressure, $\mathrm{CRP}=\mathrm{C}$-reactive protein, $\mathrm{HDL}-\mathrm{C}=$ high-density lipoprotein cholesterol, $\mathrm{LDL}-\mathrm{C}=$ low-density lipoprotein cholesterol, $\mathrm{TG}=$ triglyceride, $\mathrm{TC}=$ total cholesterol, $\mathrm{NA}=$ sodium, $\mathrm{K}=\mathrm{kalium}, \mathrm{Ca}=\mathrm{calcium}, \mathrm{Mg}=$ magnesium

\section{RESULTS}

A total of 345 patients with AAD during the study period (December 2013 to April 2017) are included in this study. Their clinical features are shown in Table 1. The in-hospital mortality rate was $21.7 \%$ in all 345 patients. This study divided the patients into a survived cohort and an in-hospital mortality cohort. Between the two groups, the demographic feature of sex $(83.7 \%$ versus $70.7 \%, P=.019)$, type A AAD (52.6\% versus $84.0 \%, P<.001)$, type of B AAD $(47.4 \%$ versus $16.0 \%, P<.01)$, smoking history $(60.7 \%$ versus $44 \%$, $P=.008)$, drinking history $(51.9 \%$ versus $36 \%, P=.019)$, admission systolic blood pressure (SBP) (147.54 \pm 32.42 versus $132.69 \pm 34.1 \mathrm{mmHg}, P=.01)$, admission diastolic blood pressure $(\mathrm{DBP})(84.00 \pm 22.64$ versus $74.29 \pm 20.86 \mathrm{mmHg}$, $P=.01)$, D-dimer $(7.9 \pm 8.6$ versus $11.7 \pm 10.65, P=.002)$, and $\mathrm{K}(3.76 \pm 0.56$ versus $5.16 \pm 10.89, P<.035)$ were significantly higher in the in-hospital mortality group than the survival group. However, no difference was found between the two groups in age, CRP, HDL-C, LDL-C, TG, TC, Na, and $\mathrm{Ca}$ (as shown in Table 1 ).

As shown in Table 2, the results of univariate analysis suggested that type $\mathrm{AAD}$ (OR 4.732, 95\% CI: 2.441 to 9.174), gender (OR 0.469 , 95\% CI: 0.259 to 0.848 ), history of smoking (OR 0.508, 95\% CI:0.303 to 0.852), history of drinking (OR 0.522, 95\% CI:0.308 to 0.886), Admission SBP (OR 0.336, 95\% CI: 0.195 to 0.580), Admission DBP (OR 0.498, 95\% CI: 0.296 to 0.838 ), D-dimer (OR 2.473, 95\% CI: 1.436 to 4.257 ), CRP (OR 1.899, 95\% CI: 1.033 to 3.492 ), LDL-C (OR 0.455 , 95\%CI: 0.243 to 0.853 ), blood Na (OR 0.564 , 95\% CI: 0.324 to 0.982$), \mathrm{K}$ (OR 2.002 , 95\% CI: 1.152 to 3.480 ) as well as $\mathrm{Ca}$ (OR 0.521,95\% CI: 0.310 to 0.876$)$ were significantly related to the in-hospital mortality in cases diagnosed with AAD (Table 2).

In multivariate logistic regression analysis, the results demonstrated that only type of AAD (OR 6.382, 95\% CI: 2.423 to 16.812 ), D-dimer (OR 2.160, 95\% CI: 1.072 to 4.350 ), and LDL-C (OR $0.373,95 \% \mathrm{CI}: 0.148$ to 0.940 ) were independently associated with in-hospital mortality in AAD patients. However, other factors which proved to be statistically significant in univariate analysis were found to be not related to prognosis in multivariate analysis (Table 3). ROC curve analysis revealed that the area under the ROC curve was 0.634 when the cutoff value of $\mathrm{D}$-dimer was set as $5.9 \mathrm{mg} / 1$. Therefore, when D-dimer level $\geq 5.9 \mathrm{mg} / \mathrm{l}$, the sensitivity and specificity were $63.4 \%$ and $58.8 \%$, respectively, in predicting in-hospital mortality in AAD patients (Figure 1). 
Table 3. Multivariate logistic regression analyses to detect the prognostic factors for in-hospital mortality in patients with AAD.

\begin{tabular}{lll}
\hline Clinical variables & OR & $95 \% \mathrm{Cl}$ \\
\hline Type of AAD (type A versus B) & 6.382 & 2.423 to 16.812 \\
Gender (male versus female) & 0.396 & 0.143 to 1.098 \\
History of drinking (yes versus no) & 0.823 & 0.344 to 1.969 \\
History of smoking (yes versus no) & 0.812 & 0.325 to 2.029 \\
Admission SBP $(\geq 120$ versus $<120), \mathrm{mmHg}$ & 0.312 to 1.682 \\
Admission DBP $(\geq 80$ versus $<80), \mathrm{mmHg}$ & 0.725 & 0.482 to 2.362 \\
D-dimer $(\geq 5.9$ versus $<5.9), \mathrm{mg} / \mathrm{L}$ & 1.067 & 1.072 to 4.350 \\
CRP $(\geq 106.5$ versus $<106.5), \mathrm{mg} / \mathrm{L}$ & 2.160 & 0.619 to 2.815 \\
LDL-C $(\geq 1.455$ versus $<1.455), \mathrm{mmol} / \mathrm{L}$ & 1.320 & 0.148 to 0.940 \\
TG $(\geq 0.655$ versus $<0.655), \mathrm{mmol} / \mathrm{L}$ & 0.373 & 0.676 to 5.624 \\
$\mathrm{Na}(\geq 136.55$ versus $<136.55), \mathrm{mmol} / \mathrm{L}$ & 1.950 & .656 \\
$\mathrm{~K}(\geq 4.025$ versus $<4.025), \mathrm{mmol} / \mathrm{L}$ & 0.479 & .454 \\
Ca $(\geq 2.145$ versus $<2.145), \mathrm{mmol} / \mathrm{L}$ & 2.009 & .873 \\
\hline
\end{tabular}

$\mathrm{OR}=$ odds ratio, $\mathrm{Cl}=$ confidence interval, $\mathrm{SBP}=$ systolic blood pressure, $\mathrm{DBP}=$ diastolic blood pressure, $\mathrm{CRP}=\mathrm{C}$-reactive protein, $\mathrm{LDL}-\mathrm{C}=$ low-density lipoprotein cholesterol, $\mathrm{TG}=$ triglyceride, $\mathrm{NA}=$ sodium, $\mathrm{K}=$ kalium

Table 4. Univariate logistic analysis in type A and B AAD patients, respectively.

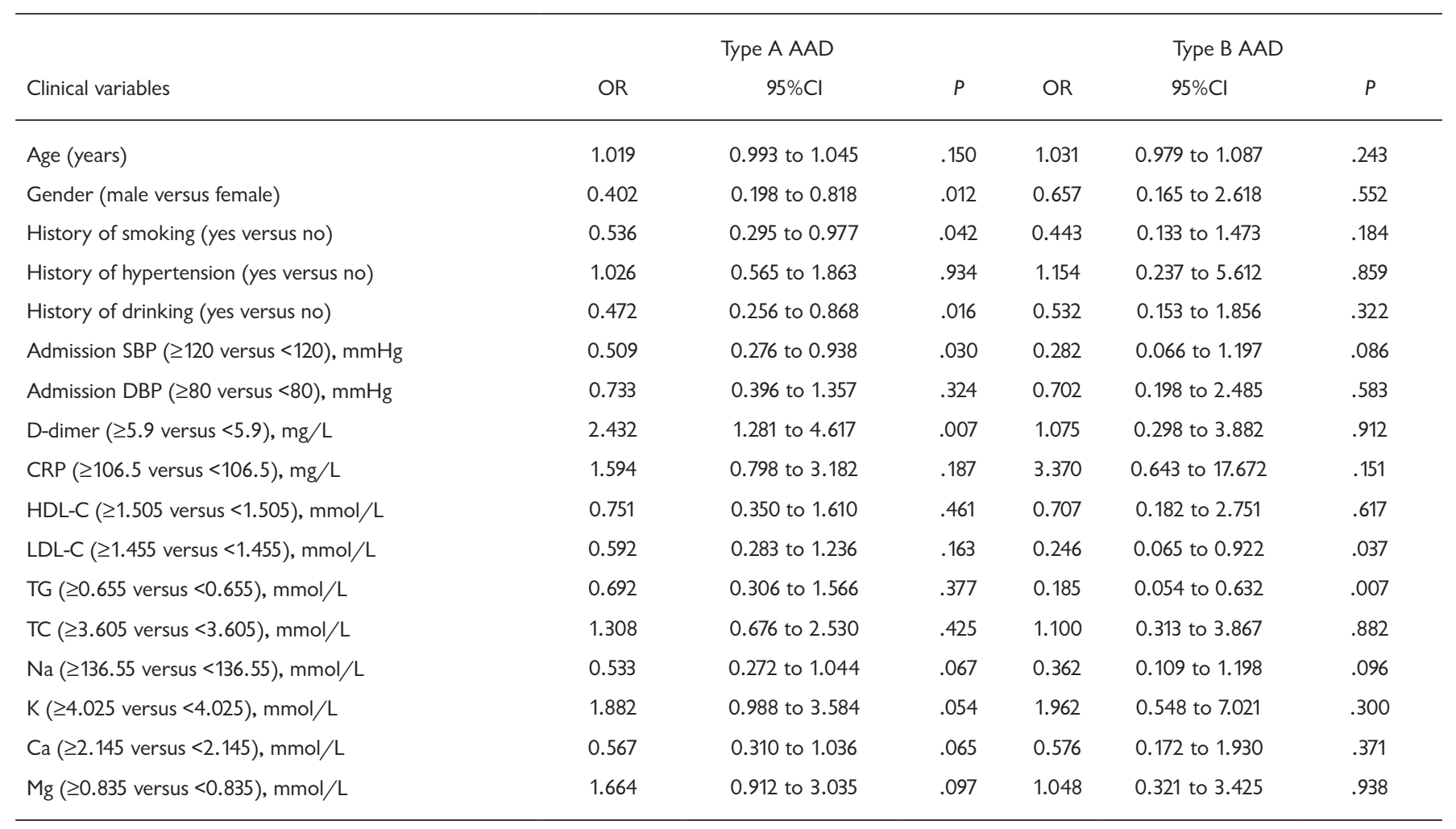

$\mathrm{OR}=$ odds ratio, $\mathrm{Cl}=$ confidence interval, $\mathrm{SBP}=$ systolic blood pressure, $\mathrm{DBP}=$ diastolic blood pressure, $\mathrm{CRP}=\mathrm{C}$-reactive protein, $\mathrm{HDL}-\mathrm{C}=$ high-density lipoprotein cholesterol, $\mathrm{LDL}-\mathrm{C}=$ low-density lipoprotein cholesterol, $\mathrm{TG}=$ triglyceride, $\mathrm{TC}=$ total cholesterol, $\mathrm{NA}=$ sodium, $\mathrm{K}=\mathrm{kalium}, \mathrm{Ca}=\mathrm{calcium}, \mathrm{Mg}=$ magnesium 
Table 5. Multivariate logistic analysis in patients with type A AAD and type B AAD, respectively.

\begin{tabular}{lll}
\hline & & Type A AAD \\
Clinical variables & OR & $95 \% \mathrm{Cl}$ \\
\hline Gender (male versus female) & 0.447 & 0.169 to 1.177 \\
History of drinking (yes versus no) & 0.766 & 0.321 to 1.832 \\
History of smoking (yes versus no) & 0.800 & 0.327 to 1.956 \\
Admission $S B P(\geq 120$ versus $<120), \mathrm{mmHg}$ & 0.335 to 1.384 \\
D-dimer $(\geq 5.9$ versus $<5.9), \mathrm{mg} / \mathrm{L}$ & 0.680 & 1.140 to 4.622 \\
$\mathrm{Na}(\geq 136.55$ versus $<136.55), \mathrm{mmol} / \mathrm{L}$ & 2.295 & 0.273 to 1.276 \\
$\mathrm{~K}(\geq 4.025$ versus $<4.025), \mathrm{mmol} / \mathrm{L}$ & 0.590 & 0.878 to 3.914 \\
Ca $(\geq 2.145$ versus $<2.145), \mathrm{mmol} / \mathrm{L}$ & 1.854 & 0.345 to 1.378 \\
$\mathrm{Mg}(\geq 0.835$ versus $<0.835), \mathrm{mmol} / \mathrm{L}$ & 0.689 & 0.857 to 3.242 \\
Type $B$ AAD & 1.667 & .625 \\
Admission $S B P(\geq 120$ versus $<120), \mathrm{mmHg}$ & & .288 \\
$\mathrm{LDL}-\mathrm{C}(\geq 1.455$ versus $<1.455), \mathrm{mmol} / \mathrm{L}$ & 0.230 & .020 \\
TG $(\geq 0.655$ versus $<0.655), \mathrm{mmol} / \mathrm{L}$ & 0.241 & .180 \\
$\mathrm{Na}(\geq 136.55$ versus $<136.55), \mathrm{mmol} / \mathrm{L}$ & 0.192 & 0.054 to 1.072 \\
\hline
\end{tabular}

$\mathrm{OR}=$ odds ratio, $\mathrm{Cl}=$ confidence interval, $\mathrm{SBP}=$ systolic blood pressure, $\mathrm{LDL}-\mathrm{C}=$ low-density lipoprotein cholesterol, $\mathrm{TG}=$ triglyceride, $\mathrm{NA}=$ sodium, $\mathrm{K}=$ kalium, $\mathrm{Ca}=$ calcium, $\mathrm{Mg}=$ magnesium

Subgroup analysis in type A AAD and B AAD was performed (Table 4). The results of univariate analysis showed that the male sex (OR 0.402, 95\%CI: 0.198 to 0.818 ), history of drinking (OR 0.472, 95\% CI: 0.256 to 0.868 ), Admission SBP (OR 0.509, 95\%CI: 0.276 to 0.938 ), D-dimer (OR 2.432, $95 \%$ CI: 1.281 to 4.617 ), $\mathrm{Na}$ (OR $0.533,95 \%$ CI: 0.272 to 1.044$), \mathrm{K}$ (OR 1.882, 95\% CI: 0.988 to 3.584 ), $\mathrm{Ca}$ (OR $0.567,95 \% \mathrm{CI}: 0.310$ to 1.036$)$, and $\mathrm{Mg}$ (OR $1.664,95 \% \mathrm{CI}$ : 0.912 to 3.035 ) were related to in-hospital mortality in cases diagnosed with A AAD. In addition, Admission SBP (OR $0.282,95 \%$ CI: 0.066 to 1.197 ), LDL-C (OR $0.246,95 \%$ CI: 0.065 to 0.922 ), TG (OR $0.185,95 \%$ CI: 0.054 to 0.632 ), and $\mathrm{Na}$ (OR 0.362, 95\%CI: 0.109 to 1.198 ) had a significant association with type $\mathrm{B} A \mathrm{ADD}$. In multivariate logistic regression analysis, the results showed that sex (OR 0.447 , $95 \%$ CI: 0.169 to 1.177 ) and D-dimer (OR 2.295, 95\% CI: 1.140 to 4.622 ) were independent prognostic factors in patients with type A AAD and only TG (OR $0.192,95 \%$ CI: 0.051 to 0.721 ) had a significant association with B AAD (Table 5).

\section{DISCUSSION}

$\mathrm{AAD}$ is a serious cardiovascular disease with a high mortality rate; it is easily misdiagnosed. In our retrospective study, we found that $\mathrm{D}$-dimer, type of $\mathrm{AAD}$, and LDL-C were independent risk factors in short-term mortality for patients with $\mathrm{AAD}$ in our multivariable Cox regression analysis. In addition, a high level of $\mathrm{D}$-dimer plays an important role in the short-term prognosis of $\mathrm{AAD}$. When the $\mathrm{D}$-dimer level was $\geq 5.9 \mathrm{mg} / \mathrm{l}$, the sensitivity and specificity were 0.634 and 0.588 in predicting in-hospital mortality, respectively. Moreover, the multivariate logistic regression analysis was performed for different types of $\mathrm{AAD}$, and results found that $\mathrm{D}$-dimer was an independent factor in A AAD and only TG was an independent factor for type $\mathrm{B} A \mathrm{AAD}$. The type of $\mathrm{AAD}$ was an independent risk factor in prognosis of $\mathrm{AAD}$, which was reported by Lingzhi et al. [Lingzhi 2016], and it was the same result in our study. Furthermore, a previous study indicated a similar result as our study, where the patients with type A AAD had a poorer short-term prognosis than patients with type B AAD [Hagan 2000].

D-dimer is a small protein fragment produced by crosslinked fibrin in the blood, and it represents the coagulation and fibrinolytic system activation. D-dimer was also treated as a diagnostic marker to help the diagnosis of AAD [Hata 2007]. The pathogenesis and prognosis of AAD in patients was based on the inflammation. Numerous recent studies have indicated that the value of $\mathrm{D}$-dimer is a reliable diagnosis marker and screening tool for AAD [Eggebrecht 2014; Weber 2003; Taylor 2013]. The sensitivity of D-dimer can reach up to $100 \%$, but with low specificity for the diagnosis of AAD [Nazerian 2014, Weber 2006]. Previously, several studies with a limited number of patients have suggested that high D-dimer levels were associated with poor shortterm outcomes and postoperative adverse events [Liu 2020; Yang 2020; Huang 2015]. Studies have revealed the coagulant material from the aortic wall released into the circulation and clotting factors accumulated at the site of the lesion during the aortic tearing, which induced the elevated level 
of D-dimer [Jan 1975]. Thus, a high level of serum D-dimer may reflect the severe and extensive aortic tearing and may act as a prognostic predictive marker for AAD. As in previously reported studies, our results strongly agree with the predictive value of $\mathrm{D}$-dimer for in-hospital mortality risk in $\mathrm{AAD}$, especially in type A AAD.

CRP is a well-known systematic inflammation marker and was proved to induce the endothelial dysfunction by stimulating the clotting system [Vrsalović 2019]. Previously reported data demonstrated $\mathrm{AAD}$ is related to inflammatory response with elevated inflammatory markers, including CRP [Duan 2018]. In a recent study, the authors found that CRP was independently associated with poor prognosis in patients with AAD [Schillinger 2002], while another report indicated that CRP remained in a normal range at admission in most AAD patients [Komukai 2005]. Specifically, in our present study, we found that CRP did not contribute to the in-hospital mortality of AAD in multivariable Cox regression analysis. Compared with previous studies, the average and median CRP values in our cohort was much higher, which reached $82.4 \mathrm{mg} / \mathrm{L}$ and $70.8 \mathrm{mg} / \mathrm{L}$, respectively. The cutoff value in another study was also set as $106.5 \mathrm{mg} / \mathrm{L}$, where the Yuden index was maximum, which was far more than that in other studies ranging from 9.8 to $20 \mathrm{mg} / \mathrm{L}$ [Vrsalović 2019].

We acknowledge there were several limitations in our study. First, this was a retrospective study performed at a single center. Second, although there was a relatively large sample in this study, further research from other centers is needed to confirm our results. We believe it is important for physicians to predict the prognosis of the patients with $\mathrm{AAD}$ at an early stage in clinical practice, so they can take advance measures to help improve patient prognosis. Finally, the long-term prognosis of our study is limited, we believe that it is necessary to explore the long-term impact of D-dimer and other blood-related parameters on the prognosis of AAD.

\section{CONCLUSION}

In summary, our study has demonstrated that D-dimer $\geq 5.9 \mu \mathrm{g} / \mathrm{mL}, \mathrm{CRP} \geq 106.5 \mathrm{mg} / \mathrm{L}$, and type A AAD were risk factors and independently associated with in-hospital mortality in AAD patients. Moreover, subgroup analysis proved that the elevated D-dimer was associated with poor prognosis in type A AAD cases. Thus, these patients with high-risk of inhospital mortality require close medical observation.

\section{REFERENCES}

Aboyans V, Ricco JB, Bartelink ML, et al. 2017. 2017 ESC Guidelines on the Diagnosis and Treatment of Peripheral Arterial Diseases, in collaboration with the European Society for Vascular Surgery (ESVS), Kardiol Pol. 75: 1065-1160.

Duan XZ, Xu ZY, Lu FL, et al. 2018. Inflammation is related to preoperative hypoxemia in patients with acute Stanford type a aortic dissection, Journal of thoracic disease. 10:1628.

Eggebrecht H, Naber CK, Bruch C, et al. 2014. Value of plasma fibrin
D-dimers for detection of acute aortic dissection, J Am Coll Cardiol. 44: 804-809.

Hagan PG, Nienaber CA, Isselbacher EM, et al. 2000. The International Registry of Acute Aortic Dissection (IRAD): new insights into an old disease, Jama. 283:897-903.

Hata M, Sezai A, Niino T, et al. 2007. Prognosis for patients with type $\mathrm{B}$ acute aortic dissection: risk analysis of early death and requirement for elective surgery, Circ J. 71: 1279-1282.

Huang B, Yang Y, Lu H, et al. 2015. Impact of d-dimer levels on admission on in-hospital and long-term outcome in patients with type A acute aortic dissection, The American journal of cardiology. 115:1595-1600.

Jan W, Timmers H, Becker AE. 1975. Coagulopathy in ruptured or dissecting aortic aneurysms, The American journal of medicine. 59:171-176.

Kalkan AK, Cakmak HA, Kalkan ME, et al. 2015.The Predictive Value of Admission Fragmented QRS Complex for In-Hospital Cardiovascular Mortality of Patients with Type 1 Acute Aortic Dissection, Ann Noninvasive Electrocardiol. 20: 454-463.

Komukai K, Shibata T, Mochizuki S. 2005. C-reactive protein is related to impaired oxygenation in patients with acute aortic dissection, Int Heart J. 46:795-799.

Lingzhi C, Hao Z, Weijian H, et al. 2016. Outcome Predictors in Patients Presenting With Acute Aortic Dissection, J Cardiothorac Vasc Anesth. 30:1272-1277.

Liu T, Zheng J, Zhang YC. et al. 2020. Association Between D-dimer and Early Adverse Events in Patients With Acute Type A Aortic Dissection Undergoing Arch Replacement and the Frozen Elephant Trunk Implantation: A Retrospective Cohort Study, Frontiers in Physiology 10.

Meszaros I, Morocz J, Szlavi J, et al. 2000. Epidemiology and clinicopathology of aortic dissection, Chest. 117:1271-1278.

Nazerian P, Morello F, Vanni S, et al. 2014. Combined use of aortic dissection detection risk score and D-dimer in the diagnostic workup of suspected acute aortic dissection, Int J Cardiol. 175: 78-82.

Nienaber CA, Powell JT. 2012. Management of acute aortic syndromes, Eur Heart J. 33: 26-35b.

Ohlmann P, Faure A, Morel O, et al. 2006. Diagnostic and prognostic value of circulating D-Dimers in patients with acute aortic dissection, Crit Care Med. 34: 1358-1364.

Peng W, Peng Z, Chai X, et al. 2015. Potential biomarkers for early diagnosis of acute aortic dissection, Heart Lung. 44:205-208.

Sakakura K, Kubo N, Ako J, et al. 2010. Peak C-reactive protein level predicts long-term outcomes in type $\mathrm{B}$ acute aortic dissection, Hypertension. 55:422-429.

Sbarouni E, Georgiadou P, Marathias A, Geroulanos S, Kremastinos DT. 2017. D-dimer and BNP levels in acute aortic dissection, Int J Cardiol. 122:170-172.

Schillinger M, Domanovits H, Bayegan K, et al. 2002. C-reactive protein and mortality in patients with acute aortic disease, Intensive Care Med. 28:740-745.

Shimony A, Filion BK, Mottillo S, Dourian T, Eisenberg MJ. 2011. Meta-analysis of usefulness of d-dimer to diagnose acute aortic dissection, Am J Cardiol. 107:1227-1234.

Taylor RA, Iyer NS. 2013. A decision analysis to determine a testing threshold for computed tomographic angiography and D-dimer in the evaluation of aortic dissection, Am J Emerg Med. 31:1047-1055. 
Tian L, Fan X, Zhu J, Liang L, Li J, Yang Y. 2014. Plasma D-dimer and in-hospital mortality in patients with Stanford type A acute aortic dissection, Blood Coagul Fibrinolysis. 25:161-166.

Vrsalović M, Presečki AV. 2019. Admission C-reactive protein and outcomes in acute aortic dissection: a systematic review, Croatian Medical Journal. 60:309.

Weber T, Hogler S, Auer J, et al. 2003. D-dimer in acute aortic dissection, Chest. 123:1375-1378.
Weber T, Rammer M, Auer J, Maurer E, Aspock G, Eber B. 2006. Plasma concentrations of D-dimer predict mortality in acute type A aortic dissection, Heart 92:836-837.

Wen D, Du X, Dong JZ, Zhou XL, Ma CS. 2013. Value of D-dimer and $\mathrm{C}$ reactive protein in predicting in-hospital death in acute aortic dissection, Heart 99. 1192-1197.

Yang G, Zhou Y, He H, Pan X, Li X, Chai X. 2020. A nomogram for predicting in-hospital mortality in acute type A aortic dissection patients, J Thorac Dis. 12:264-275. 